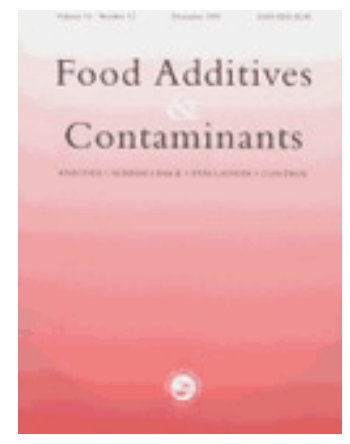

\title{
Modelling of migration from multilayers and functional barriers: estimation of parameters
}

\begin{tabular}{|c|c|}
\hline Journal: & Food Additives and Contaminants \\
\hline Manuscript ID: & TFAC-2005-303.R1 \\
\hline Manuscript Type: & Original Research Paper \\
\hline $\begin{array}{r}\text { Date Submitted by the } \\
\text { Author: }\end{array}$ & 22-Feb-2006 \\
\hline Complete List of Authors: & $\begin{array}{l}\text { DOLE, Patrice; INRA, UMR FARE } \\
\text { Voultzatis, Ioannis; INRA, UMR FARE } \\
\text { Vitrac, Olivier; INRA, UMR FARE } \\
\text { AUCEJO, Susana; TNO, Analytical Science } \\
\text { REYNIER, Alain; INRA, UMR FARE } \\
\text { HANKEMAIER, Thomas; TNO, ANALYTICAL SCIENCES } \\
\text { FEIGENBAUM, Alexandre; INRA, UMR FARE }\end{array}$ \\
\hline Methods/Techniques: & GC, Risk assessment - modelling \\
\hline Additives/Contaminants: & $\begin{array}{l}\text { Migration - diffusion, Food contact materials, Packaging recycling, } \\
\text { Packaging - migration modelling }\end{array}$ \\
\hline Food Types: & \\
\hline
\end{tabular}

\section{SCHOLARONE \\ Manuscripts}


Functional barriers modelling page 1

\section{Modelling of migration from multi-layers and functional barriers: estimation of parameters}

Patrice Dole ${ }^{\mathrm{a}}$, Yiannis Voulzatis ${ }^{\mathrm{a}}$, Olivier Vitrac ${ }^{\mathrm{a}}$, Alain Reynier ${ }^{\mathrm{a}}$, Thomas Hankemeier $^{\mathrm{b}}$, Susana Aucejo ${ }^{\mathrm{b}}$, and Alexandre Feigenbaum ${ }^{\mathrm{a}}$

(a) INRA SquAlE, Moulin de la Housse, BP 1039, 51687 Reims, France

(b) Packaging Research Group, Analytical Sciences Division, TNO-Nutrition and Food Research Institute, PO BOX 360, 3700 AJ Zeist, The Netherlands

\section{KEYWORDS}

Food packaging, migration, recycling, functional barrier, modelling, safety assessment

\footnotetext{
${ }^{1}$ Correspondence to A. Feigenbaum: alexandre.feigenbaum@ @reims.inra.fr tel: + $33-326913877$ fax: + 33-326913916
} 
Functional barriers modelling page 2

\section{ABSTRACT}

Functional barriers form parts of multilayer packaging materials, deemed to protect the food from migration of a broad range of contaminants e.g. associated with reused packaging. Often, neither the presence nor the identity of the contaminants is known, so that safety assessment of the materials has to rely on predictive tools. Several complementary freeware described here allow one to model diffusion in multi-layer films. These tools require the input of parameters which are not easy to determine or to predict. Previous work has focused on prediction of diffusion coefficients at temperatures of storage of packaging in contact with food. However many other kinetic and thermodynamic parameters are needed to describe transport properties during processing of material at high temperature and during its shelf life. All parameters needed for the calculations are discussed. In order to propose default values, the approach consists of (i) reviewing available literature data (ii) running experiments on polypropylene, polyethylene and poly(ethylene vinyl alcohol) in typical conditions (separately diffusion during processing and migration) (iii) simulating numerical sets for typical situations. Several freeware are proposed to simulate migration from multi-layers and functional barriers using the default parameters. 


\section{INTRODUCTION}

Functional barriers are used in packaging to protect food from the migration of accidental contaminants from recycled polymers. The presence of a virgin barrier layer between recycled polymer and food, delays the beginning of migration kinetics; this time delay is called lag time. The evaluation of barrier performances of a material towards a given packaging application requires (i) determination of whether contamination of the barrier occurs during processing of the multi-layer material (Pennarun et al 2004a, Franz et al 1997, Perou et al 1997) and (ii) determination as to whether the lag time for migration is lower than the shelf life of the packaging (Widen et al 2004, Pennarun et al 2005, Franz et al 1997)

As the mass transport phenomena during processing and during food contact are mainly controlled by diffusion effects, the general strategy of the food packaging scientific community was to accumulate diffusion coefficient reference data (i) at molten state for processing conditions (Pennarun et al 2004a), and (ii) at $40^{\circ} \mathrm{C}$ for food contact conditions (Dole et al, Pennarun et al 2004b, 2004c, Simal-Gandara et al 2000a, 2000b); these data, focused on low molecular weight migrants were used to complete the Piringer data bases and equations involving a large molecular weight range (Baner et al 1996, Begley et al 2005). 
However migration is obviously not controlled only by diffusion, but also by partition coefficients, heat transfer, heat diffusion, mass transfer, diffusion coefficient activation (Dole et al. 2006), and factors describing the effect of plasticization on diffusion (Reynier et al 2002). This paper addresses systematically each of these factors.

- Transport properties (matter and heat) during processing of the materials are investigated by monitoring a UV absorbing probe in the thickness of melted polymers. The parameters to be used for prediction of diffusion during processing are discussed with the background of literature data.

- Transport properties during migration step are investigated by monitoring migration of surrogates (model contaminants) from samples obtained by minimizing contamination at molten state. The parameters to be used for prediction of diffusion are discussed on the basis of literature data. Interface effects (partition and mass transfer) are discussed on the basis of numerical simulations of sets of typical situations.

The numerical tools for simulations and interpretation of experimental data were developed in the frame of this work. They are available as freeware. 


\section{Materials and surrogates}

* EVOH, HDPE and PP were supplied by Cryovac (Passirana di Rho, IT).

Model contaminants (surrogates) were chosen from the FDA and ILSI proposals (ILSI 1998). 2,5-dimethoxyacetophenone (DMA) was added as a UV marker. The final list was: Trichloroethane (Merck), toluene (Merck), chlorobenzene (Fluka), phenylcyclohexane (Merck), benzophenone (Merck), methyl margarinate (Merck), and dimethoxyacetophenone (Aldrich).

EVOH resin was impregnated with DMA according to a described procedure (Pennarun et al. 2004a).

* The impregnation of polypropylene (PP) and high density polyethylene (HDPE) both with volatile and with non-volatile surrogates was made according to a dedicated procedure (Papaspyrides et al., 2005).

\section{Measurement of DMA diffusion profiles after three- layer processing using $U V$ microspectrophotometry}

An [(ethylene - vinyl alcohol) copolymer] (EVOH) three-layer film was processed with an industrial extruder (CRYOVAC, US) at $210^{\circ} \mathrm{C}$. The inner layer was spiked with 2,5-dimethoxyacetophenone (DMA). After co-extrusion the 
sample was stored below $0^{\circ} \mathrm{C}$ to prevent further diffusion. $30 \mu \mathrm{m}$ microtomic cross sections were then analyzed with a UV microspectrophotometer (Carl Zeiss UV-visible spectrophotometer equipped with a Xenon lamp and a microscope unit for analysis of small areas). The analysed area is a circle with radius $1 \mu \mathrm{m}$. The concentration gradient of DMA is recorded from the maximum absorption peak of DMA at $330 \mathrm{~nm}$ (Pennarun et al. 2004a).

\section{Measurement of diffusion coefficients at $40^{\circ} \mathrm{C}$}

A diffusion test in a stack of films is realized according to a procedure described by Reynier (2001 $a$ and $b$ ).

\section{Migration testing}

The migration tests are made with a three-layer film in contact with a simulant.

Several three-layer film samples (virgin/contaminated/virgin layers, noted V/C/V) are prepared by co-extrusion, using a specially design of the co-extruder, in order to minimize contact time between layers at molten state. For that purpose, a Scamex (Crosnes, France) micro-extruder was equipped with a short slit die. A calander was placed at $1 \mathrm{~cm}$ after the co-extrusion die, which also contributed to minimize the cooling time. Samples were rapidly cooled at $-30^{\circ} \mathrm{C}$ just after extrusion to prevent further diffusion. Migration tests were started few hours after this processing operation. Samples with homogeneous thickness were selected, and stored at $-80^{\circ} \mathrm{C}$ to prevent losses of surrogates by evaporation and diffusion 
before the start of the migration experiments, Samples were then placed in migration cells filled with the simulant (water, ethanol, or olive oil). The cells are stored at a controlled temperature $\left(40^{\circ} \mathrm{C}\right)$ and the surrogates diffuse through the virgin polymer layer into the simulant (Figure 1). The cells are glass vials, and the sample is fitted in the cap. A different cell is used for each individual measurement. The concentration of migrating surrogates is determined at different times by analysing the simulant. In order to take into account potential variations of initial concentrations in the film, it is important to analyse also the three-layer film at the end of the migration test: the initial concentration is equal to [migrated quantity + quantity remaining in film, determined by extraction at the end of the test].

Kinetics displayed are expressed in function of $\left(t / \mathrm{L}^{2}\right)^{0.5}$ in order to take into account local variations of the thickness from sample to sample. The thickness of each sample was measured by visible microscopy.

\section{THEORETICAL BACKGROUND}

As long as the external surface remains free of contaminants, mass transport within the functional barrier is similar to that in a system with a semi-infinite geometry (no boundary effects). But when contaminants reach the interface with food, the different affinities of the contaminant with the food and with the polymer are responsible for a discontinuity of the concentration profile. The jump in concentration profiles is 
commonly described by assuming an instantaneous and local thermodynamic equilibrium between both sides of the surface, corresponding to a control by a partition coefficient (assuming a linear desorption isotherm).

Migration is obviously negligible as long as the probability of migration of a molecule is statistically "zero". This is the case e.g. when the averaged migration time required by a single molecule to reach the external surface through the functional barrier (distance $\mathrm{fb}$ ) is larger than the life time (t) of the packaging material [which is the sum of the times of processing, of storage of the empty package and of shelf life of the packaged food]. In literature, the critical migration time, following which the cumulative flux crossing the external surface can not be longer considered to be zero is calculated in several ways (Feigenbaum et al. 2005).

For longer contact times, the contamination of the contact surface is significant and previous approximations (either semi-infinite media or impervious boundary condition) are no longer valid. The mass transport description must take into account phenomena at the food-packaging boundary. The uni-directionnal and dimensionless mass transport with a constant and uniform diffusion coefficient, $\mathrm{D}$, in the packaging material is described by equation (1):

$$
\frac{\partial \mathrm{u}}{\partial \mathrm{Fo}}=\frac{\partial^{2} \mathrm{u}}{\partial \mathrm{x}^{*}} \text { with } 0 \leq \mathrm{x} * \leq 1
$$

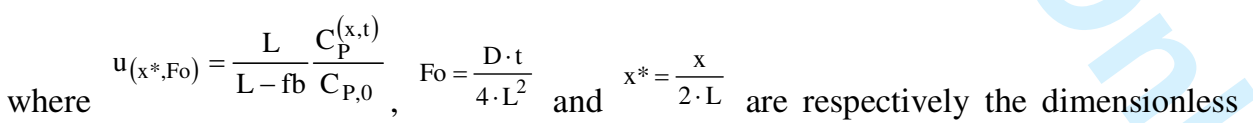
concentration (or equivalent to a Brownian density in the packaging material), time and 
position. ${ }^{\mathrm{C}_{\mathrm{P}, 0}}$ is the initial concentration in the contaminated material (expressed in $\mathrm{kg}$ of contaminant per $\mathrm{kg}$ of contaminated material), which is assumed to be homogeneous. The functional barrier is assumed to be initially non-contaminated, symmetric and located at positions $\mathrm{x}_{\mathrm{f}}{ }^{*} \mathrm{fb} /(2 \cdot \mathrm{L})$ and ${ }^{1-\mathrm{x}_{\mathrm{f}}}{ }^{*}$. The initial concentration profile is consequently ${ }^{u_{\left(-x_{f}^{*} * \leq x^{*} \leq,+x_{f}^{*}, F o=0\right)}=\frac{L}{L-f b}}$ and 0 elsewhere.

Only one side $\left(x^{*}=1\right)$ is assumed to be contact with food. The opposite side at $x^{*}=0$ is assumed to be impervious:

$$
\left\{\frac{\partial \mathbf{u}}{\partial \mathbf{x}^{*}}\right\}_{\mathrm{x}^{*}=0}=0
$$

For liquid and semi-liquid foods, the boundary condition on food side $\left(x^{*}=1\right)$ assumes a pervious contact, controlled by a partition coefficient between food and packaging, $\mathrm{K}_{\mathrm{FP}}=\frac{\left.\mathrm{v}\right|_{\mathrm{x} \rightarrow 1^{+}}}{\left.\mathrm{u}\right|_{x \rightarrow 1^{-}}}$with $\mathrm{v}$ the dimensionless concentration in food, and a mass transfer coefficient, h, given by equation (3):

$$
j^{*}=\frac{2 L}{D \cdot C_{P}, 0} j=-\left.\frac{\partial u}{\partial x^{*}}\right|_{x^{*}=1}=B i \cdot K_{F P} \cdot\left(\left.u\right|_{x^{*}=1}-\frac{\bar{v}}{K_{F P}}\right)
$$

where $\mathrm{j}$ and $\mathrm{j}^{*}$ are respectively the mass flux and the dimensionless mass flux.

$\mathrm{Bi}=\frac{\mathrm{h} \cdot 1}{\mathrm{D}}$ is the mass Biot number which represents the ratio between the internal and external resistances to mass transfer.

In a solid, the number is low. In liquids, it is much larger than 1.

$\nabla$ is the averaged dimensionless concentration in food and is inferred from a macroscopic mass balance between food and the packaging material. If the food is not initially contaminated, one gets equation (4): 


$$
\overline{\mathrm{u}}+\int_{0}^{\mathrm{Fo}} \mathrm{j} *(\tau) \cdot \mathrm{d} \tau=\overline{\mathrm{u}}+\frac{\overline{\mathrm{v}}}{\mathrm{L}_{\mathrm{PF}}}=1
$$

with $\overline{\mathrm{u}}=\int_{0}^{1} \mathrm{u}\left(\mathrm{x}^{*}, \mathrm{Fo}\right) \cdot \mathrm{dx} *$ and $\mathrm{L}_{\mathrm{PF}}=\frac{\mathrm{V}_{\mathrm{P}}}{\mathrm{V}_{\mathrm{F}}} \cdot \frac{\rho_{\mathrm{P}}}{\rho_{\mathrm{F}}}$, where $\mathrm{V}_{\mathrm{i}}$ and $\rho_{\mathrm{i}}$ are respectively the volume and the density of the phase $\mathrm{i}=\mathrm{P}, \mathrm{F}(\mathrm{P}=$ packaging material, $\mathrm{F}=$ Food $)$.

Finally, the concentration in food $\mathrm{C}_{\mathrm{F}}$, expressed in mass of migrant per mass of food is given by equation (5):

$$
\mathrm{C}_{\mathrm{F}}^{(\mathrm{Fo})}=\mathrm{C}_{\mathrm{P}, 0} \cdot\left(1-\frac{\mathrm{bf}}{\mathrm{L}}\right) \cdot \mathrm{L}_{\mathrm{PF}} \cdot \overline{\mathrm{v}}
$$

The migration rate into food is increased when the partition coefficient favours transfer into food, and when the mass transport within the food is not limiting. The worst case scenario corresponds to a zero value at the food / polymer interface, on the polymer side during the whole process (i.e. no local accumulation on the polymer side). The migration rate into the food is then controlled only by the diffusion of contaminants through the contaminated region and the functional barrier. The latter situation implies replacement of the boundary equation defined by equation (3) by equation (6):

$$
\mathrm{u}\left(\mathrm{x}^{*}=1, \mathrm{Fo}\right)=0
$$

It must be emphasized that if partition effects are significant with large Bi values (i.e. $>100$ ), differentiation of equation (4) with time for $\left.u\right|_{x^{*}=1^{-}}=\frac{\bar{v}}{K}$ leads to the following boundary condition: 
Functional barriers and multi-layer modelling

In the software Multiwise and in the following of this paper, $\mathrm{Bi}$ will be identified as $\mathrm{H}$.

\section{PRACTICAL MODELLING OF MASS TRANSPORT}

\section{Variables and input parameters}

$\mathrm{KF} / \mathrm{P}=$ partition coefficient between Food and Polymer or between liquid simulant and polymer

$\mathrm{Hl} / \mathrm{p}=$ mass transport coefficient at the food /polymer interface

$\mathrm{Hp} / \mathrm{a}=$ mass transport coefficient at the polymer / air interface

$\mathrm{Hl} / \mathrm{p} \rightarrow 0$, high resistance to mass transfer at polymer/food interface

$\mathrm{H} 1 / \mathrm{p} \rightarrow \propto$ no resistance to mass transfer at interface, worst case situation

$\mathrm{B}=$ swelling factor $(\mathrm{B}=0$ : no plasticization effect $)$

$\mathrm{C} 0=\mathrm{CP}, 0=$ Initial concentration of the contaminant in the recycled layer

$\mathrm{Cfb}, \mathrm{t}=$ concentration of the contaminant on the external surface at time

$\mathrm{fb}(\mu \mathrm{m})=$ thickness of functional barrier (In the PROCESS software, only $\mathrm{fb} / \mathrm{L}=0.33$ is currently available)

$\mathrm{L}(\mu \mathrm{m})=$ thickness of the whole material

hc $[\mathrm{W} \mathrm{m}-2 \mathrm{~s}-1]=$ heat transfer coefficient (cooling after assembling layers during process). In the Multitemp freeware, a parameter $\mathrm{H}$ is used $\mathrm{H}[\mathrm{cm} 2 \mathrm{~s}-1]=(\mathrm{Cp} * \mathrm{hc}) / \rho$. 
$\mathrm{hc}=10$ : natural cooling by convection in air hc $=50$ : cooling by forced convection in air $\mathrm{hc}=200$ : cooling by contact with a refrigerated mould wall

As pointed out the diffusion of the contaminant through the functional barrier occurs first during processing (short time but high temperature) and then during storage and finally during use of the material (possibly after hot filling). The two last steps occur around ambient temperatures.

Two coupled software have been developed in order to simulate these successive steps as they occur in real cases: the diffusion profiles (i.e. repartition of the contaminant across the thickness of the multilayer) obtained by simulating diffusion during processing (high temperature: «multitemp ») can be used as starting point of the calculation made by the second software (migration: «multiwise »). It is possible to use these several times, successively, e.g. to simulate diffusion during successive steps like processing at constant temperature, then cooling, then storage of empty package, then hot filling, then migration during storage in contact with food ...

Beta versions of the different software developed for the project can be downloaded as a freeware at: http://www.inra.fr/Internet/Produits/securiteemballage/pagefr.html. The download link goes to a folder "INRAMIG", which has to be put under C://. The ".EXE" files are located in an "APP" sub-folder. Information and assistance are found in a power point file "how to use.pps". 


\begin{abstract}
Mass transport during processing: MULTITEMP software
* Pollution of the barrier layer in the coextruder die or in the coinjection mold

Diffusion is described by the second Fick's law. The diffusion coefficient is a function of the local temperature at time t. An Arrhenius activation is assumed. Heat diffusion is described by Fourier's law. Heat transfer coefficients $\left(\mathrm{cm} \mathrm{s}^{-1}\right)$ taken into account are at polymer / mold or polymer / die interface.
\end{abstract}

* Estimation of the parameters: diffusion parameters and their thermal activation can be approximated using reference data of a fast diffusing (worst case) surrogate (see discussion below). The first problem is that it is difficult to appreciate the importance of matter losses both in the extruder and during cooling of co-extruded films. These losses are linked to the volatility of the species but also to the geometry of the machines. The "worst case approach" (for the purpose of migration prediction) consists in considering that no losses occur. The second problem is to calculate the temperature gradient across the thickness and as a function of time. This strongly depends on the heat convection parameters (i.e. in fact on the conditions of cooling) and not much on heat diffusion, which can be approximated easily by default parameters for all polymers at molten state.

\title{
Simplified tool: PROCESS software
}

A reduced number of parameters seems relevant for a rough description of diffusion during the process in worst case situations. This leads to simplified software, called PROCESS, taking into account a reduced number of variables, 
and describing qualitatively the influence of the range of their variation. PROCESS considers the type of polymer (described as the diffusion coefficient of DMA at the melt temperature), the packaging thickness range (both absolute value of thickness $\mathrm{L}$ - from $10 \mu \mathrm{m}$ to $20 \mathrm{~mm}$ - of material and relative thickness of the functional barrier $\mathrm{fb}$ - arbitrarily taken as $33 \%$ in the first version of the software), the extrusion time (see below), the extrusion temperature and the heat transfer coefficient hc (from 10 to $200 \mathrm{~W} \mathrm{~m}^{-2} \mathrm{~s}^{-1}$, considered here as a flux). PROCESS considers a residence time in a mould or in a co-extrusion dye at a constant temperature, followed by a convective cooling down to room temperature, with an overall duration of both stages of 60 s. PROCESS calculates abacuses of percentages of concentration of DMA (the model contaminant) of the functional barrier (average concentration) and of the external surface (local concentration).

Assumptions: mass transport is assumed with impervious boundary conditions, and is activated with temperature according to an Arrhenius relation. Heat transfer is assumed to be purely diffusive and controlled by an apparent diffusion coefficient constant for all polymers. As a result, source terms are arbitrary distributed through the whole thickness of the material. Diffusion coefficients and activation energies (Pennarun 2004a) used are those of DMA. PROCESS does not calculate the results, but selects them from a data base of pre-calculated situations, choosing the closest to the problem raised. PROCESS generates almost instantaneously a result, selected from more than 10000 different conditions (in the range of input variables) in the database of simulated results. New results are 


\section{Migration of contaminants into food: MULTIWISE software}

* Migrant diffusion

The diffusion is described by the second Fick's law. The diffusion coefficient is a function of the local concentration of food constituents (or of the food simulant) in the plastic at time t. One diffusion coefficient of a given surrogate is defined for each layer in absence of food constituent; its value is allowed to vary with the local concentration of the swelling simulant. An exponential relation between $\mathrm{D}$ and food constituent (simulant) concentration is assumed.

$\mathrm{D}$ at $\mathrm{t}=$ initial $\mathrm{D}$ [entered value] $\times \exp (\mathrm{B} \times$ simulant concentration at $\mathrm{t})$

The parameter B characterises the swelling effect of the food constituent (simulant). When $\mathrm{B}=0$, the diffusion coefficient does not depend on the simulant concentration - no "swelling" nor "plasticizing" effect.

* Influence of Food sorption

Food sorption is described by the second Fick's law. The diffusion coefficient of food constituents into the polymer is a function of the local food concentration at 
time t. An exponential relationship between Dfood and food concentration is assumed.

* Mass transfer of contaminant at interfaces:

$\mathrm{HP} / \mathrm{a}$ and $\mathrm{Hl} / \mathrm{P}$ are the mass transfer coefficients at the polymer /air and at the liquid (food) / polymer interfaces. Three different situations are generally possible for $\mathrm{H}(\mathrm{HP} / \mathrm{a}$ and $\mathrm{HI} / \mathrm{P})$ parameters:

$\mathrm{H}$ is equal to zero: no transfer is possible at this interface (e.g. the additive not soluble or not volatile, or the external medium is a metallic substrate).

$\mathrm{H}$ is "infinite": the transfer from the interface is instantaneous. As the external volume is considered infinite, the concentration on the surface is equal to zero.

$\mathrm{H}>0$ but low: in this case, desorption or migration of the contaminant is partly controlled by its rate of evacuation at air or food interfaces.

Mass transfer coefficients can be assumed equal to zero at the interface with air.

\section{Simplified tool: Storage software:}

STORAGE simulates the migration of different contaminants from recycled plastic films (in symmetrical materials containing a functional barrier) into food during contact with food.

As for PROCESS, STORAGE is based on a database of simulated results. New results are either linearly or non linearly (cubic Hermite interpolation) interpolated through a suitable grid of reference conditions. 
Functional barriers and multi-layer modelling

Inputs: $\mathrm{L}(10 \mu \mathrm{m}$ to $20 \mathrm{~mm}), \mathrm{fb}(5$ to $40 \%), \mathrm{D}\left(10^{-7}\right.$ to $\left.10^{-14} \mathrm{~cm}^{2} \cdot \mathrm{s}^{-1}\right), \mathrm{t}$ (0 to 730 days)

Output: level of migration into food.

Assumptions: A diffusive mass transport is assumed, with a worst case scenario: no external resistance between film and food. A one side contact is assumed.

Note: in the software available on the web site, for simplification, the hc (MULTITEMP), Hl/p (MULTIWISE) parameter are just named $\mathrm{H}$. Hp/a is not taken into account. $\mathrm{Hl} / \mathrm{p}$ can be adjusted.

\title{
RESULTS AND DISCUSSIONS
}

\section{A) Diffusion during processing of functional barriers}

\author{
An experiment conducted on a plant, with DMA as surrogate, diffusing in a \\ multilayer during processing. The DMA distribution displayed in Figure 2 has \\ been obtained after processing a [virgin EVOH/EVOH (+DMA)/virgin EVOH] \\ $80 \mu \mathrm{m}$ thick three-layer at $210^{\circ} \mathrm{C}$. \\ Two essential observations can be made: (i) the virgin layer is contaminated and \\ (ii) the diffusion has reached the external surface. The slope of the profile near the \\ surface suggests an external rate limiting desorption by evaporation.
}


This profile shape can be simulated by numerical calculation assuming that the diffusion behaviour of $\mathrm{EVOH}[\mathrm{D}=\mathrm{f}(\mathrm{T})]$ is a simplified two-step process:

- first, isothermal contact in the extruder die with no possible matter nor heat (both $\mathrm{H}=0$ ) exchange with the outside of the system;

- then, a contact between layers during cooling in air (variation of $\mathrm{T}$ versus time and space), with the possibility of mass transfer outside the system (evaporation). Temperature profiles simulated from (i) classical heat diffusion coefficients of polymers $\left(1.6 \cdot 10^{-7} \mathrm{~m}^{2} \cdot \mathrm{s}^{-1}\right)$ (ii) a simplified description of cooling after the extrusion die, assuming no change of state leading to non continuous variation of parameters and constants of diffusion or of heat delivery.

Figures 3 and 4 correspond to profiles calculated to simulate the experimental data of Figure 2, with the assumption that with $\mathrm{H} 1 / \mathrm{P}=0.001$ (fast evaporation) and $\mathrm{Hl} / \mathrm{P}=0 \mathrm{~m} \mathrm{~s}-1$ (no evaporation) respectively. These profiles look very different. The corresponding migration kinetics resulting from these materials should be different, but in both cases, the lag times should be equal to zero.

However, the possibility to fit these specific data as in Figure 3 should not be considered as a validation of a model, since the concentration 0 at the polymer / air interface as well as the profile shape suggest that an important evaporation has taken place. Modelling of evaporation would involve too many parameters, most of them being difficult to evaluate, such as the average (in the considered temperature range) rate of evaporation at the surface, the temperature profiles... This is why the overestimation method should in first instance be used as an indicative tool to decide whether a pollution of the barrier layer is likely or not to 
Functional barriers and multi-layer modelling

occur during processing. This should be sufficient to describe most practical situations, which are expected to be close to either of the two extreme situations:

- When there is no significant pollution of the barrier during processing, the migration step can be calculated independently assuming no pollution at all (vertical profiles). With PET, it has been shown experimentally that the pollution of a functional barrier of a bottle is negligible during processing (Pennarun $\mathrm{et} \mathrm{al}$. 2004a).

- When the pollution of the barrier is important, no further calculations are necessary, the barrier is not efficient, and, as far as a quick decision must be taken, the system should not be used as a functional barrier.

However, in intermediate situations, or to define acceptable conditions of use, it is necessary to simulate the process, which requires a good knowledge of the system studied, in terms of heat exchange especially.

If the main criteria for safety assessment of a material depend on whether the contaminant has reached the surface in contact with the food (see the discussion on lag time), it is possible to use a simplified description of the process, neglecting evaporation of the surrogates:

- if the barrier is efficient during processing, surface phenomena have no influence on the migration, since the migrant has not reached the interface after processing

- if the barrier is not efficient, no further calculations are necessary. 
Selection of functional barrier materials on the basis of behaviour during processing

The simplified description used in PROCESS allows classifying the polymers in function of their diffusion behaviour at their melt temperature.

The thickness needed to maintain $\mathrm{Cfb} \leq 0.05 \mathrm{C} 0$, at different processing temperatures was calculated for all the polymers in the data base of PROCESS. These times should not be considered as absolute values, as they are calculated in extremely worst case: the diffusion coefficients used are those of DMA. $\mathrm{hc}=255$ $\mathrm{W} \mathrm{m}{ }^{-2} \mathrm{~s}^{-1}$, relative functional barrier thickness is $1 / 3$ of the whole material, and the process time te $=0.1 \mathrm{~s}$. This time is of course not realistic and is used only as reference value for the classification. On Figure 5, each label mentions polymer type and processing temperature. Based on the behaviour of DMA, polymers which are glassy at room temperature are by far the best diffusion barriers.

PET, PVC, PAN, PVDC, EVOH, PA > PS > Polyolefins, EVA

Figure 5 allows interpretations like: "a $50 \mu \mathrm{m}$ PVDC functional barrier is equivalent to $10000 \mu \mathrm{m}$ LLDPE”.

The classification thus obtained corresponds roughly to the efficiency of gas barrier polymers: the higher is the glass temperature, the better is the barrier. Again, since this scale is based on the behaviour of DMA, it may take into account specific interactions of this surrogate with the polymer. 


\section{Which parameters can be used for prediction of diffusion during processing?}

For prediction purpose, four parameters are essential: D, hc, Ea and HP/a. Let us examine these parameters one by one.

\section{What about $D$ and Ea during processing?}

In the software, the diffusion coefficient and the activation energy used are those of DMA, the reference compound. This is probably a worst case, as DMA has a low molecular weight: low molecular weight substances have high diffusion coefficients and low activation energies (Dole et al. 2006). In case of recycling, where the identity of the possible contaminant is unknown, one should take into account such worst case, lower molecular weight reference compounds. This should not lead to major differences as the dependence of $\mathrm{D}$ with molecular weight is expected to be low at high temperature (Dole et al. 2006). However it would be interesting to have D and Ea data available for several reference compounds, with different chemical groups, in order to better take into account possible specific [diffusant - polymer] interactions. The activation energies measured for DMA in melted polymers were up to $110 \mathrm{~kJ} / \mathrm{mole}$ in polyacrylonitrile (Pennarun et al. 2004a). Since the worst case corresponds to the lowest value (slightest decrease of D during cooling), more information should be obtained in this field. When using the MULTITEMP software to describe the diffusion of an unknown contaminant, a default value of $50 \mathrm{~kJ} / \mathrm{mole}$ is recommended for diffusion in melted state. 


\section{What about hc?}

The larger is hc, the quicker is the cooling and the steeper is the decrease of D once the layers are assembled. In the case of PET co-injection, different scenarios, corresponding to basically different cooling conditions, were envisaged. Typical values:

$$
\begin{aligned}
& \mathrm{hc}=255 \mathrm{~W} \mathrm{~m}^{-2} \mathrm{~s}^{-1}: \text { describes cooling of a mould with water at } 8^{\circ} \mathrm{C} \\
& \mathrm{hc}=100 \mathrm{~W} \mathrm{~m}^{-2} \mathrm{~s}^{-1} \text { : cooling in an air stream; } \\
& \mathrm{hc}=10 \mathrm{~W} \mathrm{~m}^{-2} \mathrm{~s}^{-1} \text { : cooling by natural convection of air }
\end{aligned}
$$

The worst case situation in all cases would be $\mathrm{hc}=0 \mathrm{~W} \mathrm{~m}^{-2} \mathrm{~s}^{-1}$. But this has no meaning, as the polymer would not be allowed to cool.

hc values have therefore to be measured in a process, which can be achieved with an infrared camera, by following surface - temperature kinetics.

\section{What about Hp/a?}

If evaporation takes place during processing (large $\mathrm{Hp} / \mathrm{a}$ ), the average and the surface concentration of the contaminant (and consequently its migration) will be lower (see figure 2), which contributes to the consumer's safety. The current version of MULTITEMP however describes processing in a mold, which is a worst case situation $(\mathrm{Hp} / \mathrm{a}=0$, no evaporation). The future version will include this variable. Hp/a values can be determined according to Vergnaud (1991).

\section{B) Migration through functional barriers}


The aim of this part of the work is to establish whether the simplified model MULTIWISE, with a simple set of default parameters, assuming complete migration at equilibrium and no rate limiting mass transfers, can describe the initial part of migration kinetics. The early stages of migration are the most critical in terms of risk assessment of the capacity of a functional barrier to protect a food.

The first step was to measure intrinsic diffusion coefficients of the surrogates in the polymer, i.e. values which could be considered as true values, not apparent values. This required tests conducted in absence of liquid simulants, which often plasticize the polymers. The Moisan test is well adapted to this requirement (table $1)$.

The second step was to apply the simplified model to fit experimental migration kinetics from three-layer materials (prepared with the contaminated layer as middle layer) into olive oil and ethanol. The experiments were run for a complete set of surrogates in PP and in HDPE. Kinetics are shown for HDPE in Figure 6. The experiments were carefully designed, as follows: (i) PP and HDPE, which are poor barriers, were used in order to have quick results (ii) the total thickness (about $300 \mu \mathrm{m}$ ) was adjusted to have a lag time of several hours. Use of a microextruder allowed minimising the diffusion in the molten state, due to a very short contact time at high temperature; moreover a calander was placed at $1 \mathrm{~cm}$ after the co-extrusion die, which also contributed to minimize diffusion during the 
cooling time. It could thus be assumed that no diffusion occurred during the processing step. In order to have also no diffusion between date of processing and date of start of migration tests, the samples were stored at $-30{ }^{\circ} \mathrm{C}$ immediately after their processing.

Intrinsic (in HDPE films) and apparent (into simulants) diffusion coefficients were determined from Moisan tests and for migration (from HDPE three-layers into ethanol and olive oil) experiments respectively (Table 1). Fits of experimental results were made with MULTIWISE, assuming very large values of $\mathrm{Hl} / \mathrm{P}=1$ (equivalent to $\mathrm{Hl} / \mathrm{P}$ tends to $\infty$ ). These $\mathrm{D}$ values all lie in the same order of magnitude, which suggests that the approach should be further simplified, and that swelling effects by the food could be neglected.

On the other hand, it may seem surprising at first glance that apparent diffusion coefficients with olive oil are not higher than intrinsic ones, and that plasticization of the functional barrier does not play a role. This apparent contradiction can be solved by considering general knowledge on plasticization: all surrogates in this experiment are low molecular weight species (the low molecular weight was one of the criteria for the selection of surrogates), which are less influenced by plasticization than higher molecular weight compounds, like normal additives (Reynier et al. 2002). 
Migration of trichloroethane from PP/PP-surrogate/PP three-layers into water leads to a different behaviour. Experimental lag times in water are larger than with ethanol and with olive oil (compare Figure 6 and Figure 7). Similar results are obtained for all the other hydrophobic surrogates, like toluene and chlorobenzene. As we have seen above, this cannot be attributed to plasticization. Considering the partition coefficient of these hydrophobic surrogates does not explain such changes in lag time values. We therefore investigated the possible role of the rate limiting mass transfer $(\mathrm{Hl} / \mathrm{P})$ parameter on the migration of these lipophilic surrogates from a lipophilic polymer into water. A simulation of migration was made using MULTIWISE, assuming a three-layer structure, and different $\mathrm{Hl} / \mathrm{P}$ values: $\mathrm{Hl} / \mathrm{P}=10^{-11}, 10^{-10}, 10^{-9}, 10^{-8}$ and $1(\mathrm{Hl} / \mathrm{P} \rightarrow \infty) \mathrm{cm} \mathrm{s}^{-1}$ (figure 8). It appears that there is a considerable effect on lag time.

By contrast, benzophenone, which has more affinity to the aqueous acidic simulant, has a lag time identical in the three simulants tested (Figure 9). It seems that when there are no rate limiting mass transfer effects, the lag times are identical and depend mainly on diffusion effects. Despite the considerable work in 
literature on migration, there is still little information about such interface effects. The rate limiting mass transfer parameter (called "convection factor" by Vergnaud) (Vergnaud 1991) is usually considered to depend mainly on the liquid in contact (food or food simulant). Our results suggest that Hl/P could also strongly depend on the structure of the migrant, which requires further exploration (Mougharbel et al. submitted).

Prediction of migration kinetics: which values are to be used for the calculations?

\section{What about D in storage conditions?}

Diffusion coefficients at ambient temperature can be approximated using reference data obtained with fast diffusing, low molecular weight probes tabulated for 14 polymers (Dole et al. 2006, Feigenbaum et al. 2005). For other polymers, they can be approximated using an empirical structure / diffusion coefficient relationships such as the Piringer equation (Begley et al. 2005), which overestimates the actual values (worst case). In the general case, the use of an "intrinsic" diffusion coefficient (measured by the Moisan or by the three-layer test) is a good predictive tool with an acceptable approximation.

\section{What about assuming $K F / P=I n f i n i t e ?$}

Simulations of migration kinetics for different $\mathrm{K}$ values (Figure 10) indicate that partition effects influence mainly the second part of the kinetics, after the lag 
time. Even if the entire kinetics (a) are different, the initial parts (b) are very similar. No significant differences are observed during the lag time period [see also first time derivatives (c) and (d) respectively] in the initial stages of the mass transfer into the liquid (before maximum flux / see time derivative kinetics). The second part is of little interest if we focus on a rough idea of the lag time, for instance to compare a lag time with a shelf life when the functional barrier efficiency has to be evaluated. If one is interested only by the lag time period, using MULTIWISE with the assumption $\mathrm{K}=$ infinite (or in practice any arbitrary value) leads to a correct estimation of the lifetime. STORAGE, the simplified software, does not take into account $\mathrm{K}$ values.

\section{What about assuming $\mathrm{Hl} / \mathrm{p} \rightarrow$ Infinite?}

Three different situations of the mass transfer coefficient $\mathrm{Hl} / \mathrm{P}$ are possible:

$\mathrm{Hl} / \mathrm{P}=0$ : no migration. This value of the parameter can be used in Multiwise to describe diffusion during storage of empty containers before packaging foods for non volatile contaminants.

$\mathrm{Hl} / \mathrm{P}=1(\mathrm{Hl} / \mathrm{P} \rightarrow$ infinite): this is the (worst) case generally used; the partition equilibrium on the surface is instantaneously reached.

$\mathrm{Hl} / \mathrm{P}>0$ but low (in the $10^{-11}-10^{-8}$ range): in this case, the migration of the contaminant is partly controlled by its rate of evacuation from interface to food.

Since the prediction of $\mathrm{Hl} / \mathrm{P}$ values has never been studied in literature, it is unfortunately not possible to propose a better approach. Assuming $\mathrm{H} \rightarrow$ infinite is 
an overestimation, contributing to a worst case approach, but very far from the behaviour of real viscous foodstuffs.

\section{What about the partition coefficient at barrier / polymer interface: diffusion and solubility barriers?}

The influence on migration of the partition coefficient of the migrant between polymer layers is illustrated on Figure 11. This is obtained by a simulation using MULTIWISE, for a three-layer material, with the contaminant initially located in layer 2, diffusing trough the barrier (layer 1) before migrating into food. If the substance has a polarity very different from that of the barrier, its partition coefficient between layers 1 and 2 may change dramatically. In all simulations, the diffusion coefficients in all layers are the same: $\mathrm{D}=4.410^{-9} \mathrm{~cm}^{2} \mathrm{~s}^{-1}$, which corresponds to trichloroethane in polypropylene, calculated from the Piringer equation (Begley et al. 2005). It is seen that this partition coefficient strongly influences the migration kinetics, but has no influence on the lag time.

This is the case of polar substances, coming from instance from a polar substrate like paper (here layer 3). If the barrier is apolar (like polypropylene), the migration of the polar substance will be kept to a very low level even after the lag time.

This illustrates that numerous possibilities exist to design a functional barrier, by playing on the diffusion behaviour, but also on the partition behaviour between 
Functional barriers and multi-layer modelling

\section{CONCLUSION}

In principle, a large set of parameters is needed to assess the efficacy of a functional barrier: diffusion coefficients, activation energy, mass transfer coefficients at the different interfaces and partition coefficients, plasticization parameters.

It is possible to simulate the behaviour of functional barriers, using some assumptions for the parameters.

Parameters which are overestimated:

the diffusion coefficients at melted state (Pennarun et al. 2004a) and at $40^{\circ} \mathrm{C}$ (Feigenbaum et al. 2005, Dole et al. 2006).

$\mathrm{KF} / \mathrm{P}$ : for a worst case, and for comparing predicted migration to a legal limit, $\mathrm{K}$ has to be overestimated, and KF/P = infinite can be used. Nevertheless, if the criteria for evaluation of the functional barrier is the lag time, $\mathrm{KF} / \mathrm{P}$ has no influence and any value can be taken.

$\mathrm{Hl} / \mathrm{p}$ : can be assumed infinite. But as it is a critical value, it could be determined with model migration experiments from very thin films (few $\mu \mathrm{m}$ ). 
Parameters which have to be determined: hc

PROCESS proposes default values. As it plays a major role, hc should be experimentally determined from surface temperature kinetics (Pennarun et al. 2004a).

Parameters for which there is no value currently available:

The activation energy of diffusion in melted state, Ea, is also a key parameter. The lower Ea, the larger is the barrier pollution. DMA in different polymers display very large differences. In PROCESS, these values are used. But the structure of the migrant probably plays an important role, which has not been studied up to now. Pending more data, we propose to use an average value $\mathrm{Ea}=50$ $\mathrm{kJ} \mathrm{mol}^{-1}$.

The partition coefficients between polymer layers have a very important effect on migration kinetics, but only a reduced effect on the lag time. In the FAIR project, we focused on functional barriers linked to restricted diffusion properties. With such diffusion barriers, the larger the molecular weight of the migrant, the lower its diffusion coefficient (at least in first approximation) and the larger the barrier effect. This work also illustrates how functional barriers may work based on opposite polarities and poor solubility of the migrant in the barrier. Solubility barriers act in a complementary mechanism, reducing the migration of substances 
Functional barriers and multi-layer modelling

\section{ACKNOWLEDGEMENT}

The work reported here was achieved in the frame of the FAIR CT984318 EUfunded research programme. The European Commission DG Research, the Region Champagne Ardenne and Institut National de la Recherche Agronomique are acknowledged for financial support of this work. 


\section{References}

Baner, A.; Brandsch, J.; Franz, R.; Piringer, O., 1996: The application of a predictive migration model for evaluating the compliance of plastic materials with European food regulations. Food Additives and Contaminants, 13, 587-601. Begley T., Castle L., Feigenbaum A., Franz R., Hinrichs K., Lickly T., Mercea P., Milana M., O’Brien A., Rebre S., Rijk R., Piringer O., 2005: Evaluation of migration models that might be used in support of regulations for food-contact plastics Food Additives and Contaminants, 22, 73-90

Dole P., Feigenbaum A. E., de la Cruz C., Pastorelli S., Paseiro P., Hankemeier T., Voulzatis Y., Aucejo S., Saillard P., Papaspyrides C. 2006: Typical diffusion behavior in packaging polymers. Application to functional barriers, accepted in Food Additives and Contaminants, 23, 202-211

Feigenbaum A., Dole P., Aucejo S., Dainelli D., de la Cruz Garcia C., Hankemeier T., N'Gono Y., Papaspyrides C.D., Paseiro P., Pastorelli S., Pavlidou S., Pennarun P.Y., Saillard P., Vidal L., Vitrac O., Voulzatis Y., 2005: Functional Barriers: properties and evaluation, Food Additives and Contaminants, 22, 956-967

Franz, R.; Huber, M.; Piringer, O., 1997: Presentation and experimental verification of a physicomathematical model describing the migration across functional barrier layers into foodstuffs. Food Additives and Contaminants 14, 
Functional barriers and multi-layer modelling

627-640.

ILSI, International Life Science Institute, 1998: Recycling Plastics for Food Contact Use, guidelines, ILSI Europe, Avenue E. Mounier 83, B-1200 Brussels, Belgium

Mougharbel A., Feigenbaum A., Vitrac O, 2006: Interfacial mass transport properties which control the migration of packaging constituents into foodstuffs; Journal of Food Engineering, to be published

Papaspyrides C.D., Voultzatis Y., Pavlidou S., Tsenoglou C., Dole P., Feigenbaum A., Paseiro P., Pastorelli S., de la Cruz Garcia C., Hankemeier T., S. Aucejo, 2005: A New Experimental Procedure for Incorporation of Model Contaminants in Polymer Hosts, Progress in Rubber, Plastics and Recycling Technology, 21, 243-260.

Pennarun P. Y., Ngono Y., Dole P., Feigenbaum A., 2004a: Functional barriers in PET recycled bottles. Part II: diffusion of pollutants during processing, Applied polymer science, 92, 2859-2870 Pennarun, P. Y.; Dole, P.; Feigenbaum, A., 2004b: Overestimated diffusion coefficients for the prediction of worst case migration from PET: Application to recycled PET and to functional barriers assessment. Packaging Technology and Science 17, 307-320

Pennarun P. Y., Dole P., Feigenbaum A., 2004c: - Functional barriers in PET recycled bottles. Part I. Determination of diffusion coefficients in bioriented PET with and without contact with food simulants, Journal of Applied Polymer 
Functional barriers and multi-layer modelling

Science, 92, 2845-2858

Pennarun P. Y., Dole P., Feigenbaum A., 2005: - Experimental direct evaluation of functional barriers in PET recycled bottles. Comparison of migration behaviour of mono and multilayers, Packaging Technology and Science, 18, 107 123

Perou, A. L.; Vergnaud, J. M., 1997: Contaminant transfer during the coextrusion of food packages made of recycled polymer and virgin polymer layers.

Computational and Theoretical Polymer Science, 7, 1-6.

Pez-Carballo GL, Cava D., Lagaroä JM, Catalaä RM , and Gavara R, 2005:

Characterization of the Interaction between Two Food Aroma Components, $\alpha$ -

Pinene and Ethyl Butyrate, and Ethylene-Vinyl Alcohol Copolymer (EVOH)

Packaging Films as a Function of Environmental Humidity, J. Agric. Food

Chem., 53, 7212-7216

Reynier, A.; Dole, P.; Feigenbaum, A., 2001a: Diffusion coefficients of additives in polyolefins (2), influence of swelling and temperature on $\mathrm{D}=\mathrm{f}(\mathrm{MW})$ correlations Journal of Applied Polymer Science, 82, 2434-2443

Reynier, A.; Dole, P.; Humbel S., Feigenbaum, A.: 2001b: Diffusion coefficients of additives in polyolefins (1), correlation with geometric parameters. Journal of Applied Polymer Science, 82, 2422-2433

Reynier, A.; Dole, P.; Feigenbaum, A., 2002: Migration of additives from polymers into food simulants: numerical solution of a mathematical model taking into account food and polymer interactions. Food Additives and Contaminants, 
Functional barriers and multi-layer modelling

19, 89-102.

Simal-Gandara J.; Sarria-Vidal M.; Rijk R., 2000a: Tests of potential functional barriers for laminated multilayer food packages. Part II: Medium molecular weight permeants. Food Additives and Contaminants, 17, 815-819

Simal-Gandara J; Sarria-Vidal M; Koorevaar A; Rijk R, 2000b: Tests of potential functional barriers for laminated multilayer food packages. Part I: Low molecular weight permeants, Food Additives and Contaminants, 17, 703-711

Vergnaud J.M., 1991, Liquid transport in polymeric materials: modeling and industrial applications, Ed. Prentice Hall, Englewood Cliffs, New Jersey, USA. Widen, H.; Leufven, A.; Nielsen, T. Migration of model contaminants from PET bottles: influence of temperature, food simulant and functional barrier. (2004), Food Additives \& Contaminants 21(10), 993-1006 


\section{CAPTIONS}

Table 1: diffusion coefficients of surrogates, obtained by the Moisan method and by migration experiments from (HDPE/HDPE-surrogates/HDPE) sandwiches $(300 \mu \mathrm{m})$

Figure 1: Principle of the migration test: a three-layer (Virgin/Contaminated/Virgin films) is in contact with the simulant on one side, in a stainless steel cell

Figure 2: Experimental 2,4-Dimethoxyacetophenone distribution in a multilayer [EVOH/EVOH-DMA/EVOH] after processing at $210^{\circ} \mathrm{C}$. Possible fits are on figure 3.

Figure 3: DMA diffusion profile corresponding to an evaporation of the diffusant at the surface with $\mathrm{HP} / \mathrm{a}=0.001 \mathrm{~m} \mathrm{~s}^{-1}$

Figure 4: DMA diffusion profiles, assuming no evaporation at the surface $(\mathrm{HP} / \mathrm{a}=$ $\left.0 \mathrm{~m} \mathrm{~s}^{-1}\right)$

Figure 5: Classification of functional barrier efficacy: thickness needed to get the concentration on the surface in contact with food at $5 \%$ of the initial concentration 
in the recycled layer, based on very worst case D (diffusion coefficient of DMA;

Pennarun et al. 2004a). Simulated with PROCESS for $\mathrm{hc}=255 \mathrm{~W} \mathrm{~m}^{-2} \mathrm{~s}^{-1}$, process time $0.1 \mathrm{~s}$. Functional barrier thickness is $1 / 3$ of the whole material thickness.

Each label mentions polymer type and processing temperature.

Figure 6: Migration kinetics at $40^{\circ} \mathrm{C}$ of trichloroethane from [Virgin

PP/contaminated PP/Virgin PP (300 $\mu \mathrm{m})]$ into olive oil and ethanol

Figure 7: Migration kinetics at $40^{\circ} \mathrm{C}$ of trichloroethane from [Virgin PP/contaminated PP/Virgin PP $(300 \mu \mathrm{m})]$ three-layers into water. The vertical line indicates the lag time with olive oil and with ethanol

Figure 8: influence on migration kinetics and on lag time of the food/polymer mass transfer coefficient. Calculation made with MULTIWISE, assuming a three layer material $(25-50-25 \mu \mathrm{m})$, the migrant is initially in layer $3\left(\mathrm{C}_{1, \mathrm{t}=0}=0, \mathrm{C}_{2, \mathrm{t}=0}=\right.$ $\left.0, \mathrm{C}_{3, \mathrm{t}=0}=500 \mathrm{mg} / \mathrm{kg}\right)$, with $\mathrm{Kpol} 1 / \mathrm{pol} 2=\mathrm{Kpol} 2 / \mathrm{pol} 3=1, \mathrm{KF} / \mathrm{P}(\mathrm{Kliquid} / \mathrm{pol} 1)=$ $1 ;$ Dpol1 $=$ Dpol2 $=$ Dpol3 $=4.410^{-11} \mathrm{~cm}^{2} \mathrm{~s}^{-1}$.

Figure 9: Migration kinetics at $40{ }^{\circ} \mathrm{C}$ of Benzophenone from [Virgin PP/contaminated PP/Virgin PP $(300 \mu \mathrm{m}$ ] three-layers into water. 
Figure 10: simulation of migration kinetics, using different food/packaging partition coefficients $\mathrm{a}, \mathrm{b}: \mathrm{Fc}=$ migration $\left(\mathrm{kg} \mathrm{m}^{-2}\right) ; \mathrm{c}$, d: derivative of migration $\left(\mathrm{kg} \mathrm{m}^{-2} \mathrm{~s}^{-1}\right) \mathrm{b}$ and $\mathrm{d}$ are enlargements of a and c respectively

Figure 11: simulation of the influence on migration of the partition coefficient between polymer layers in a system:

FOOD / POLYMER $1(250 \mu \mathrm{m}) /$ POLYMER $2(500 \mu \mathrm{m}) /$ POLYMER $3(250 \mu \mathrm{m})$

(K12) is the partition coefficient between polymer layers 1 and $2, \mathrm{~K} 23=\mathrm{KF} / 1=$ 1, all other parameters being identical. Calculation with MULTIWISE, assuming all the migrant initially in layer $2\left(C_{1, t=0}=0, C_{2, t=0}=500, C_{3, t=0}=0 \mathrm{ppm}\right)$. The diffusion coefficient is $4.310^{-9} \mathrm{~cm}^{2} \mathrm{~s}^{-1}$ in all polymer layers. 


\begin{tabular}{|c|c|c|c|}
\hline & \multicolumn{3}{|c|}{ Diffusion coefficient D $\left(10^{-10} \mathrm{~cm}^{2} \mathrm{~s}^{-1}\right)$} \\
\hline & $\begin{array}{l}\text { Moisan test } \\
\text { ("intrinsic" D) }\end{array}$ & \multicolumn{2}{|c|}{$\begin{array}{l}\text { Migration experiment with three- } \\
\text { layer material (apparent D) }\end{array}$} \\
\hline Simulant $\rightarrow$ & None & Ethanol & Olive oil \\
\hline$\downarrow$ Surrogate & 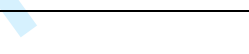 & & \\
\hline Toluene & 24 & 18 & 15 \\
\hline Chlorobenzene & 26 & 20 & 14 \\
\hline $\begin{array}{l}1,1,1- \\
\text { Trichloroethane }\end{array}$ & 6.5 & 3.8 & 2.9 \\
\hline Phenylcyclohexane & 2.7 & 1.9 & 1.6 \\
\hline Benzophenone & 1.8 & 3.8 & 3.2 \\
\hline Methyl margarinate & 1.7 & 1.7 & 0.8 \\
\hline
\end{tabular}

Table 1: diffusion coefficients of surrogates, obtained by the Moisan method and by migration experiments from (HDPE/HDPE-surrogates/HDPE) sandwiches $(300 \mu \mathrm{m})$ 
Figure 1: Principle of the migration test: a V/C/V three-layer

(Virgin/Contaminated/Virgin) is in contact with the simulant on one side, in a stainless steel cell 
Figure 2: Experimental 2,4-Dimethoxyacetophenone distribution in a multilayer [EVOH/EVOH-DMA/EVOH] after processing at $210^{\circ} \mathrm{C}$. Possible fits are on figure 3. 
Figure 3: 2,5-dimethoxyacetophenone diffusion profiles ( corresponding to an evaporation of the diffusant at the surface with $\mathrm{HP} / \mathrm{a}=0.001 \mathrm{~m} \mathrm{~s}^{-1}$

Concentration (arbitrary units) 
Functional barriers and multi-layer modelling

\section{Concentration (arbitrary units)}

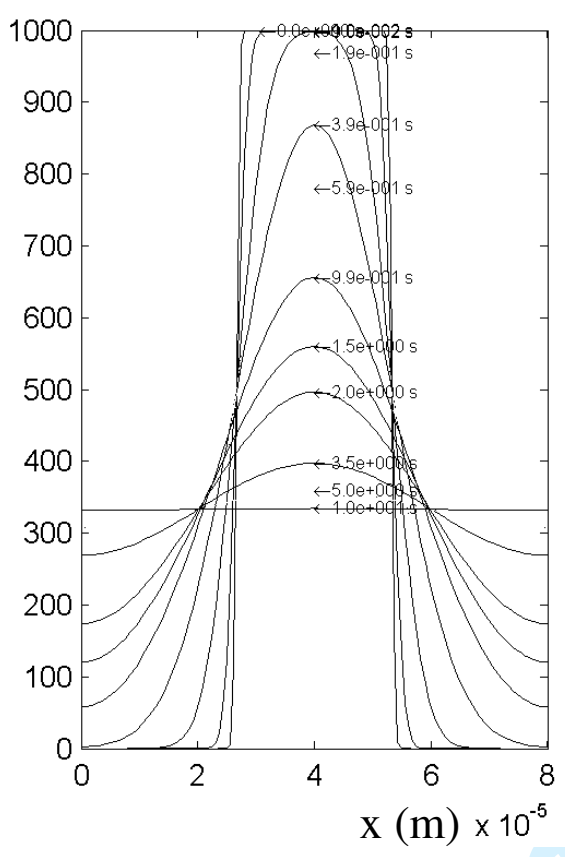

Concentration (arbitrary units)

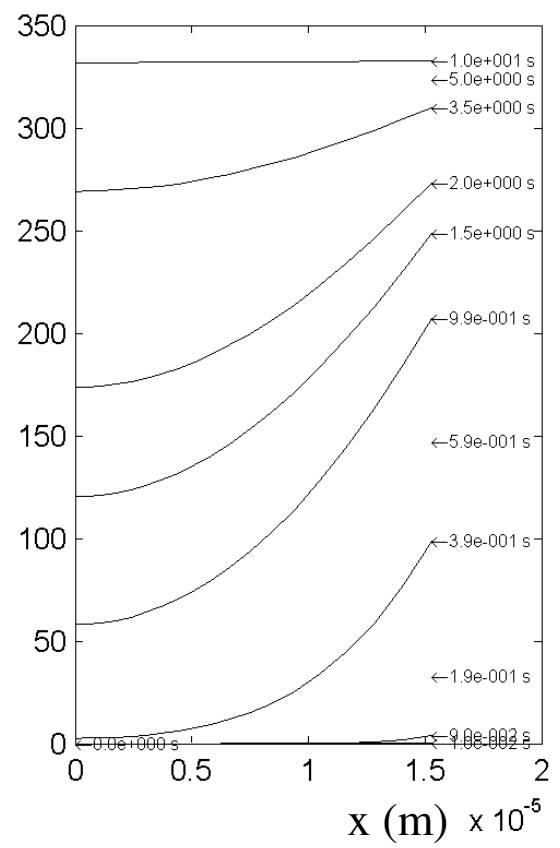

Figure 4: DMA diffusion profiles, assuming no evaporation at the surface $(\mathrm{HP} / \mathrm{a}=$ $0 \mathrm{~m} \mathrm{~s}-1)$. Figure on the right is an expansion of the interface region. 
Figure 5: Classification of functional barrier efficacy: thickness needed to get the concentration on the surface in contact with food at $5 \%$ of the initial concentration in the recycled layer, based on very worst case D (diffusion coefficient of DMA; Pennarun et al. 2004a). Simulated with PROCESS for hc $=255 \mathrm{~W} \mathrm{~m}^{-2} \mathrm{~s}^{-1}$, process time $0.1 \mathrm{~s}$. Functional barrier thickness is $1 / 3$ of the whole material thickness. Each label mentions polymer type and processing temperature. 
Functional barriers and multi-layer modelling

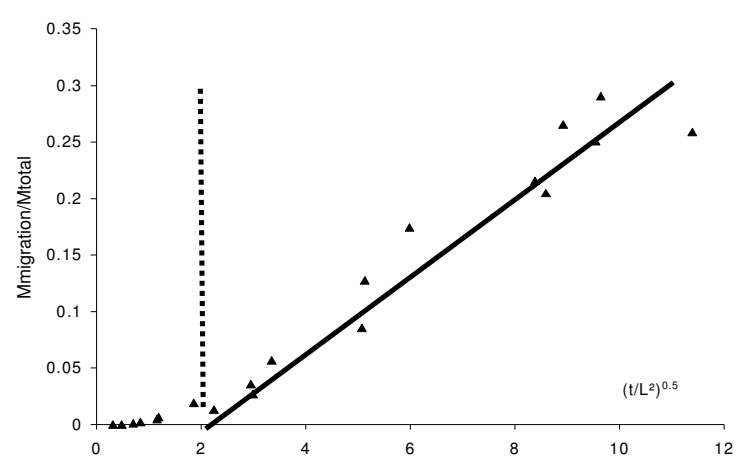

Olive oil

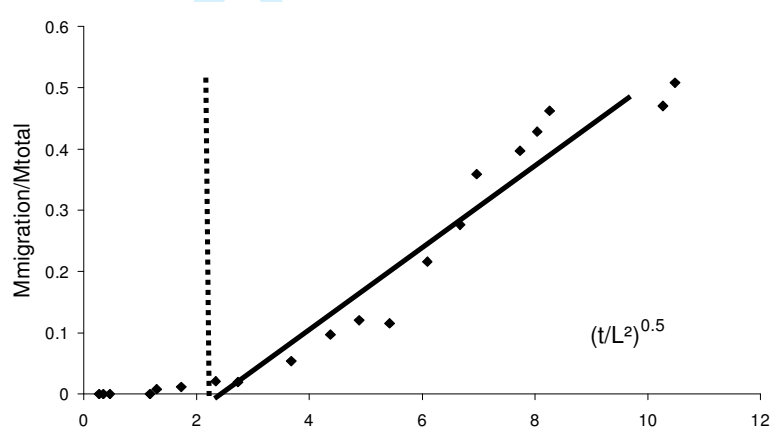

\section{Ethanol}

Figure 6: Migration kinetics at $40^{\circ} \mathrm{C}$ of trichloroethane from [Virgin PP/contaminated PP/Virgin PP $(300 \mu \mathrm{m}]$ into olive oil and ethanol $[\mathrm{t}$ in $\mathrm{h}, \mathrm{L}(\mu \mathrm{m})$ is the functional barrier layer thickness] 


\begin{abstract}
Figure 7: Migration kinetics at $40^{\circ} \mathrm{C}$ of trichloroethane from [Virgin PP/contaminated PP/Virgin PP $(300 \mu \mathrm{m})]$ three-layers into water. The vertical line indicates the lag time with olive oil and with ethanol $[\mathrm{t}$ in $\mathrm{h}, \mathrm{L}(\mu \mathrm{m})$ is the functional barrier layer thickness].
\end{abstract}


Figure 8: influence on migration kinetics and on lag time of the food/polymer mass transfer coefficient. Calculation made with MULTIWISE, assuming a three layer material $(25-50-25 \mu \mathrm{m})$, the migrant is initially in layer $3\left(\mathrm{C}_{1, \mathrm{t}=0}=0, \mathrm{C}_{2, \mathrm{t}=0}=\right.$ $\left.0, \mathrm{C}_{3, \mathrm{t}=0}=500 \mathrm{ppm}\right)$, with $\mathrm{Kpol} 1 / \mathrm{pol} 2=\mathrm{Kpol} 2 / \mathrm{pol} 3=1, \mathrm{KF} / \mathrm{P}(\mathrm{Kl} / \mathrm{pol} 1)=1$; Dpol1 $=$ Dpol2 $=$ Dpol3 $=4.410^{-11} \mathrm{~cm}^{2} \mathrm{~s}^{-1}$ 


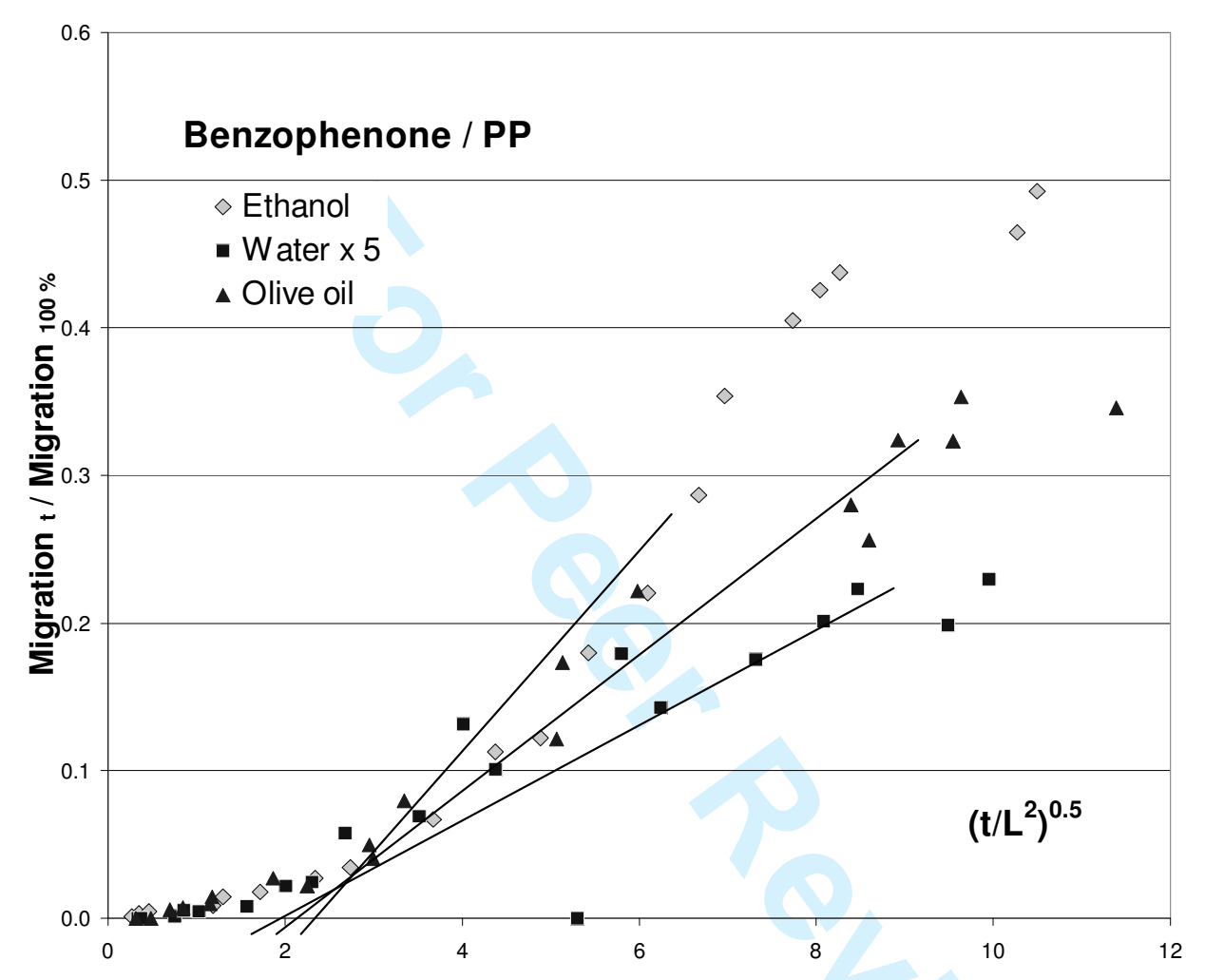

Figure 9: Migration kinetics at $40{ }^{\circ} \mathrm{C}$ of Benzophenone from

[Virgin PP/contaminated PP/Virgin PP (300 $\mu \mathrm{m})]$ three-layers into water [t in h, L $(\mu \mathrm{m})$ is the functional barrier layer thickness]. 
a)
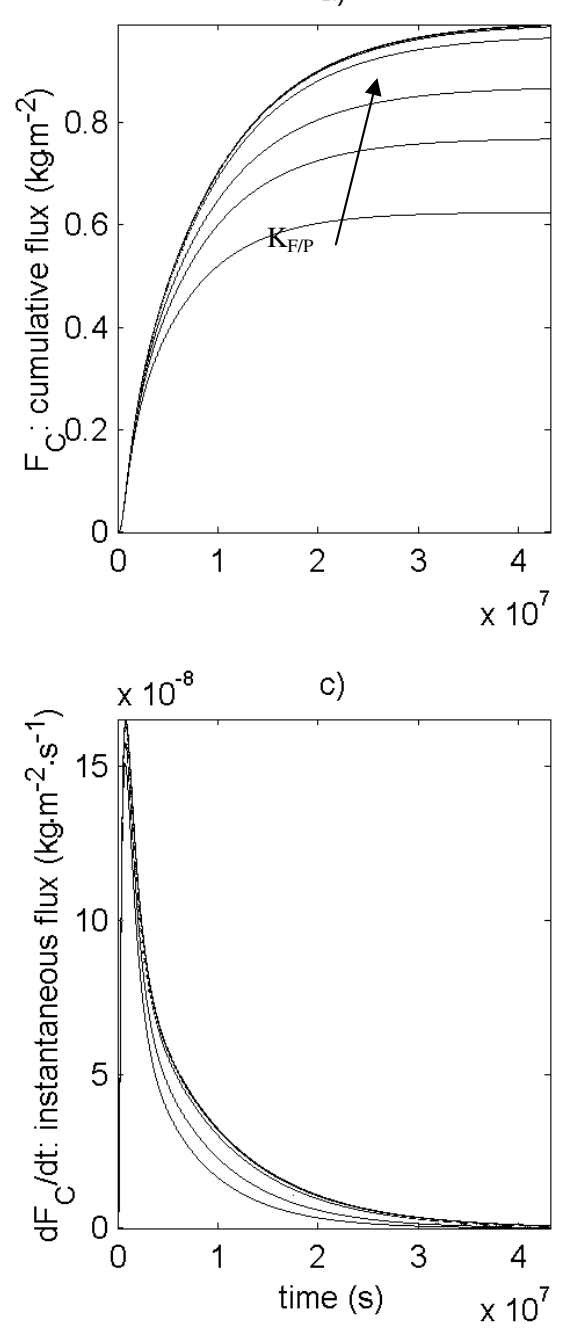

b)

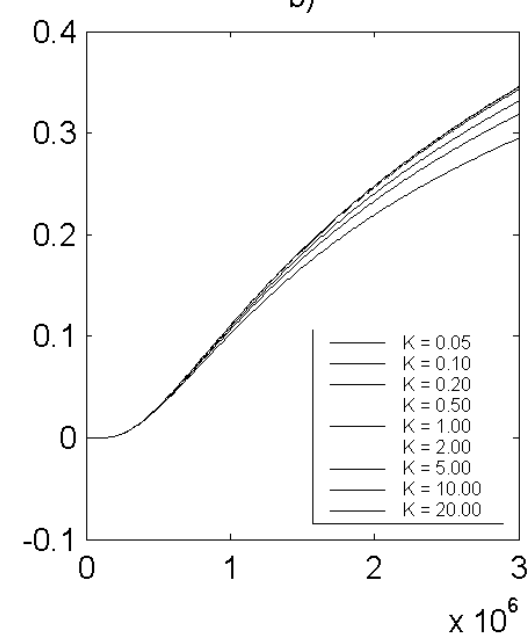

d)

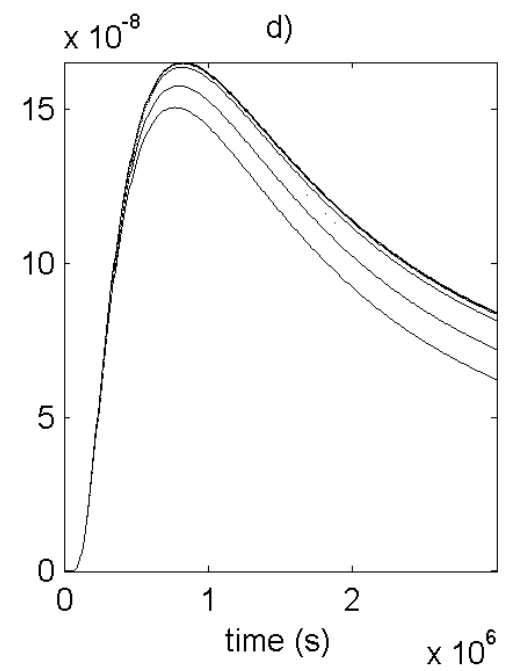

Figure 10: simulation of migration kinetics, using different food/packaging partition coefficients: $\mathrm{a}, \mathrm{b}: \mathrm{Fc}=$ migration $\left(\mathrm{kg} \mathrm{m}^{-2}\right) ; \mathrm{c}, \mathrm{d}$ : derivative of migration $\left(\mathrm{kg} \mathrm{m}^{-2} \mathrm{~s}^{-1}\right)$

$\mathrm{b}$ and $\mathrm{d}$ are enlargements of a and c respectively 


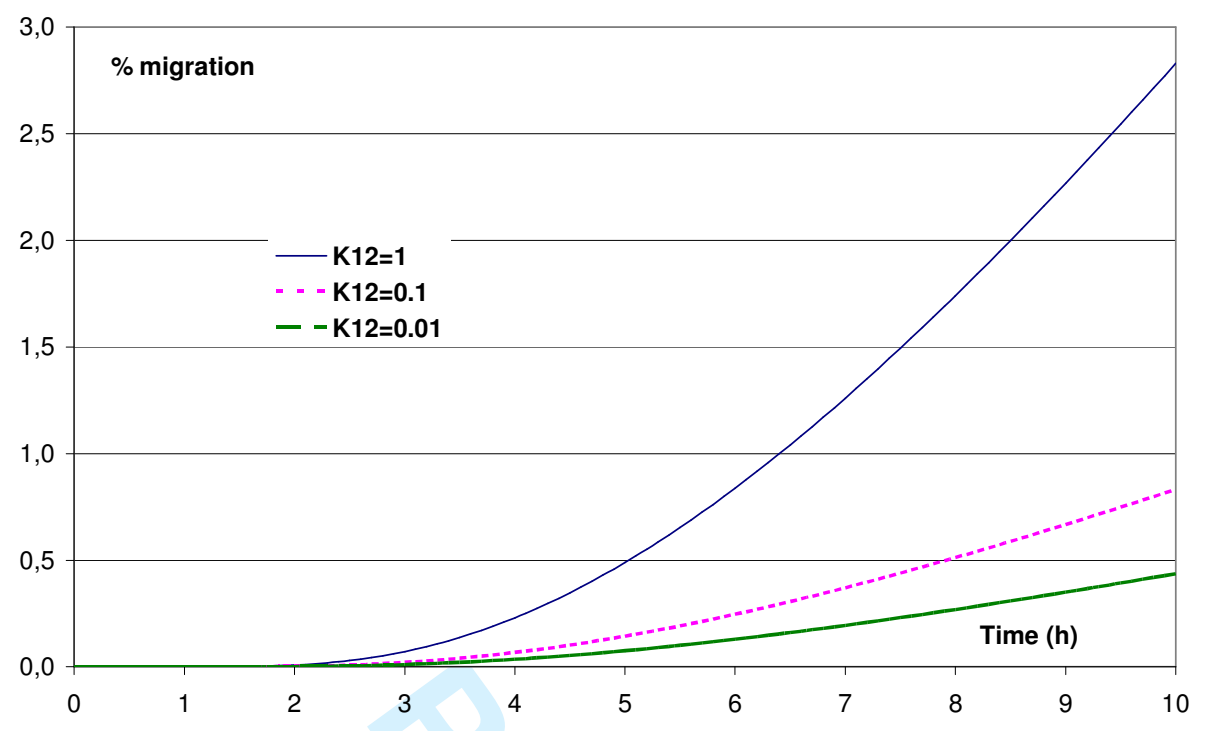

Figure 11: simulation of the influence on migration of the partition coefficient between polymer layers in a system:

FOOD / POLYMER $1(250 \mu \mathrm{m})$ / POLYMER $2(500 \mu \mathrm{m}) /$ POLYMER $3(250 \mu \mathrm{m})$ (K12) is the partition coefficient between polymer layers 1 and $2, \mathrm{~K} 23=\mathrm{KF} / 1=1$, all other parameters being identical. Calculation with MULTIWISE, assuming all the migrant initially in layer $2\left(\mathrm{C}_{1, t=0}=0, \mathrm{C}_{2, \mathrm{t}=0}=500, \mathrm{C}_{3, \mathrm{t}=0}=0 \mathrm{ppm}\right)$. The diffusion coefficient is $4.310^{-9} \mathrm{~cm}^{2} \mathrm{~s}^{-1}$ in all polymer layers. 